\title{
A Preliminary Study of Age and Sex of People with Hemophilia
}

\author{
Shaofang Yang1, Miao Ge1*, Shanxi Liu²*, Yiguo Liu², Minyi Cen1', Chiqin Pan ${ }^{3}$ \\ ${ }^{1}$ Institute of Healthy Geography, College of Tourism and Geographical, Shaanxi Normal University, Xi'an, China \\ ${ }^{2}$ Hemophilia Research Group, Hematology Institute of Shaanxi Medical University, Xi'an, China \\ ${ }^{3}$ Forestry Survey of Sarft in Guizhou Province, Guiyang, China \\ Email: yangsf_111@snnu.edu.cn, yangsf_111@nwsuaf.edu.cn, *gemiao@snnu.edu.cn, *liusx139@163.com, \\ liuyiguo100@163.com,305991661@qq.com,387801584@qq.com
}

How to cite this paper: Yang, S.F., Ge, M., Liu, S.X., Liu, Y.G., Cen, M.Y. and Pan, C.Q. (2017) A Preliminary Study of Age and Sex of People with Hemophilia. Health, 9, 401408.

https://doi.org/10.4236/health.2017.93028

Received: February 6, 2017

Accepted: March 6, 2017

Published: March 9, 2017

Copyright $\odot 2017$ by authors and Scientific Research Publishing Inc. This work is licensed under the Creative Commons Attribution International License (CC BY 4.0).

http://creativecommons.org/licenses/by/4.0/

\begin{abstract}
Aim: This paper aims at providing more information of people with hemophilia for more targeted treatment. Methods: 1149 people with hemophilia are surveyed in 45 units, and then established by EpiData software. The number of people with hemophilia in 9 age intervals for the male and female is analyzed by Population Pyramid and Pareto Analysis. Results: It is found that the people with hemophilia are appearing in every age interval. Relative to the number of male patients, the number of female patients is extremely rare. Of 1134 male patients, relative frequencies for male ranked the first (23.0\%), second (17.4\%), third (17.2\%) are $7-12,2-3,13-18$ years old, respectively, while of 15 female patients, relative frequencies for female in these age intervals are only $13.3 \%, 13.3 \%, 6.7 \%$, respectively. However, the most relative frequency of female patients is between $26-45$ years old. Conclusion: There is a challenge of the aging hemophilia population. Most of male patients are between $7-12$ and $2-3$ years old. Most of female patients are between $26-45$ years old.
\end{abstract}

\section{Keywords}

Hemophilia, Survey, Age, Sex

\section{Introduction}

Hemophilia, an X-linked genetic blood disorder that affects boys and men primarily, is the most well-known [1] [2] [3] [4]. Women carry the gene and their sons develop the disease [5] [6]. Hemophilia is one of genetic disorders characterized particularly by three highs (high bleeding rate, high mortality and high morbidity). The hallmark of haemophilic bleeding manifestation is haemarthroses, 
most frequently in severe disease with elbows, knees, and ankles most commonly affected. Repeated haemarthroses lead to arthropathy [3]. Nowadays, hemophilia is harmful, distributed widely and lack of effective treatment measure [7], which causes great pain, burden and economic crisis to patients and their family. In order to supply assistance treatment information of hemophilia, many researchers have studied demographic characteristics, quality of life, age, sex, etc. [8]-[13]. Patricia A. et al. [8] studied health information of 1243 women with hemophilia aged 18 - 25 years. C. Hermans et al. [9] researched the clinical management of older people with hemophilia. However, there is no report on special age and sex of people with hemophilia [8]-[16]. The present paper focuses on hemophilia patient's age and sex for providing more information for patients with hemophilia in order for more targeted treatment.

\section{Materials and Methods}

The method of sampling survey is used in this study. The people with hemophilia from various administrative units (hospitals and research institutes) were collected in China. The inclusion standard: the subjects who participate in the study are in accordance with the diagnostic criteria of World Federation of Hemophilia (WFH): hemophilia A (HA) and hemophilia B (HB), which are hereditary X-chromosomal recessive disorders caused by deficiency or absence of coagulation factors VIII (encoded by F8) or IX (encoded by F9), respectively [3]. The exclusion standard: the congenital genetic disease deficiency of other coagulation factors, von willebrand disease ( $\mathrm{vWF}$ ), and the disease deficiency of vitamin $\mathrm{K}$ are all eliminated. 1149 people with hemophilia were tested in 45 units distributed randomly the North District, the East District, the Northeast District, the Central south District, the Southwest District, and the Northwest District in China. These units were located in 20 provinces, cities, special administrative regions, and autonomous regions of China. These people with hemophilia were located in 256 cities and counties from 30 provinces, cities, special administrative regions, and autonomous regions of China. The age of the subjects ranged from 0 to 75 years old.

The database with 1149 cases is established by EpiData software [17] after finishing encoding data.

According to the United Nations age interval, the age interval is divided into juveniles (age $<18$ years), youth (age $\in[18,45)$ years), mid adults (age $\in[45$, $59)$ years), and the elderly (age $\in[59,75)$ years) (Table 1 ).

\section{Results}

\subsection{Statistical Analysis}

A total of 1149 people with hemophilia have been researched, of which hemophilia A (HA) is 1000 cases, hemophilia B (HB) is 149 cases (Table 2). Most of the subjects are han nationality, is 1131 cases, which account for $85.2 \%$ of the total.

Table 3 presents most of the patients are juveniles aged 0 - 18 years old, which 
Table 1. Relative frequency of patients in different age intervals.

\begin{tabular}{|c|c|c|c|c|}
\hline Category & The standard & Category & The standard & Age interval (year) \\
\hline \multirow{5}{*}{ Juveniles } & \multirow{9}{*}{$\begin{array}{l}\text { The United } \\
\text { Nations ages }\end{array}$} & Baby & \multirow{5}{*}{ Chinese children ages } & $0-1$ \\
\hline & & Infancy & & $2-3$ \\
\hline & & Pre-school age & & $4-6$ \\
\hline & & School age & & $7-12$ \\
\hline & & Teenagers & & $13-18$ \\
\hline \multirow[b]{2}{*}{ Youth } & & Young adults & \multirow{2}{*}{ The United Nations ages } & $19-25$ \\
\hline & & Youth & & $26-45$ \\
\hline Mid adults & & Mid adults & The United Nations ages & $46-59$ \\
\hline The elderly & & The elderly & The United Nations ages & $60-75$ \\
\hline
\end{tabular}

Table 2. Relative frequency of types of people with hemophilia

\begin{tabular}{ccc}
\hline Type & Number of patients & Relative frequency (\%) \\
\hline Hemophilia A (Factor VIII) & 1000 & 87.0 \\
Hemophilia B (Factor IX) & 149 & 13.0 \\
Total & 1149 & 100.0 \\
\hline
\end{tabular}

Table 3. Relative frequency of patients in different age intervals.

\begin{tabular}{cccc}
\hline Category & Age interval (year) & Number of patients & Relative frequency (\%) \\
\hline Juveniles & $0-18$ & 786 & 68.4 \\
Youth & $18-45$ & 338 & 29.4 \\
Adults & $45-59$ & 23 & 2.0 \\
The elderly & $60-75$ & 2 & 0.2 \\
Total & Total & 1149 & 100.0 \\
\hline
\end{tabular}

account for $68.4 \%$ of the total, followed by the youth aged 18 - 45 years old, which account for $29.4 \%$ of the total. Fewer patients are adults aged $45-59$ and the elderly aged 60 - 75 years old. However, of 1149 people with hemophilia, 25 people are over 45 years old. It is a remarkable fact that there is more aging hemophilia population.

In order to differentiate and comprehensive the number of each age interval more obviously. It is important to subdivide age intervals according to the United Nations ages and Chinese children ages. Table 4 shows relative frequency of patients in different age intervals. The most number of patients are in $7-12$ age intervals which are 263 numbers of patients and constitute $22.9 \%$, followed by the patients aged 1 - 3 years are 199 numbers of patients and constitute $17.3 \%$. The least number of patients are in $60-75$ age intervals which are 2 numbers of patients and constitute $0.2 \%$.

\subsection{Pareto Analysis and Population Pyramid Analysis}

Study the number of each age interval for male and female with Population 
Table 4. Relative frequency of patients in different age intervals.

\begin{tabular}{cccc}
\hline Category & Age interval (year) & Number of patients & Relative frequency (\%) \\
\hline Baby & $0-1$ & 37 & 3.2 \\
Infancy & $2-3$ & 199 & 17.3 \\
Pre-school age & $4-6$ & 91 & 7.9 \\
School age & $7-12$ & 263 & 22.9 \\
Teenagers & $13-18$ & 196 & 17.0 \\
Young adults & $19-25$ & 171 & 14.9 \\
Youth & $26-45$ & 167 & 14.5 \\
Mid adults & $46-59$ & 23 & 2.0 \\
The elderly & $60-75$ & 2 & 0.2 \\
Total & Total & 1149 & 100.0 \\
\hline
\end{tabular}

Pyramid Analysis and Pareto Analysis [18]. Table 5 presents relative frequency of patients in different age intervals for male and female. Figure 1 shows Pareto analysis summarizing the number of the male in different age interval and Pareto analysis based on the cumulative percentages. Figure 2 shows Pareto analysis summarizing the number of the female in different age interval and Pareto analysis based on the cumulative percentages.

A total of 1149 patients are researched, of the 1134 (98.7\%) patients are male, and $15(1.3 \%)$ patients are female. For the male, the number ranked the first (261), second (197), third (195) are 7 - 12, 2 - 3, 13 - 18 years old, which relative frequency is $23.0 \%, 17.4 \%, 17.2 \%$. The least number is in $60-75$ years old, which relative frequency is only $0.1 \%$ (Table 5 , Figure 1 ). For the female, the relative frequency in $7-12,2-3,13-18$ years old is only $13.3 \%, 13.3 \%, 6.7 \%$, respectively. The most number is between 26 - 45 years old, which relative frequency is as much as $40.0 \%$, while the least number is in $46-59$ and $0-1$ years old (Table 5, Figure 2).

Although from the point of single gender, the most number of female patients is in 26 - 45 years old, which relative frequency is as much as $40.0 \%$. However, in contrast to the number of male patients, the number of female patients is extremely rare (Figure 3 ).

In Figure 3, red represents the number of the male with hemophilia; green represents the number of the female with hemophilia. It shows that compared with the male, the number of women can slightly displayed only in 26 - 45 years old from nine age intervals.

\section{Discussion}

Our results show that hemophilia $\mathrm{A}$ is more common than hemophilia $\mathrm{B}$; the number of the male with hemophilia is far more than the female, and most of patients are juveniles aged 0 - 18 years old, which coincide with the biology characteristics of hemophilia [1] [2] [3] [4] [19]. Hemophilia is X-linked recessive disease, 
Table 5. Relative frequency of patients in different age intervals for male and female.

\begin{tabular}{cccc}
\hline \multirow{2}{*}{ Category } & Age interval (year) & Male $(\mathrm{N}=1134)$ & Female $(\mathrm{N}=15)$ \\
\cline { 3 - 4 } & & $\mathrm{N}(\%)$ & $\mathrm{N}(\%)$ \\
\hline Baby & $0-1$ & $37(3.3 \%)$ & $0(0.0 \%)$ \\
Infancy & $2-3$ & $197(17.4 \%)$ & $2(13.3 \%)$ \\
Pre-school age & $4-6$ & $89(7.8 \%)$ & $2(13.3 \%)$ \\
School age & $7-12$ & $261(23.0 \%)$ & $2(13.3 \%)$ \\
Teenagers & $13-18$ & $195(17.2 \%)$ & $1(6.7 \%)$ \\
Young adults & $19-25$ & $170(15.0 \%)$ & $1(6.7 \%)$ \\
Youth & $26-45$ & $161(14.2 \%)$ & $6(40.0 \%)$ \\
Mid adults & $46-59$ & $23(2.0 \%)$ & $0(0.0 \%)$ \\
The elderly & $60-75$ & $1(0.1 \%)$ & $1(6.7 \%)$ \\
Total & Total & $1134(100.0 \%)$ & $15(100.0 \%)$ \\
\hline
\end{tabular}

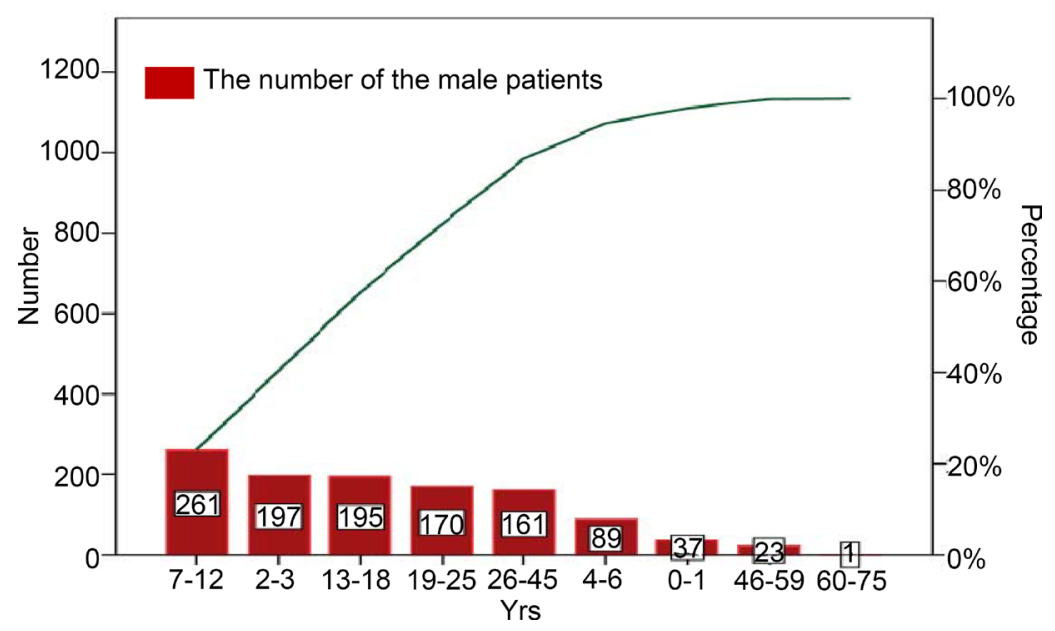

Figure 1. Pareto analysis summarizing the number of the male with hemophilia in different age intervals and Pareto analysis based on the cumulative percentages.

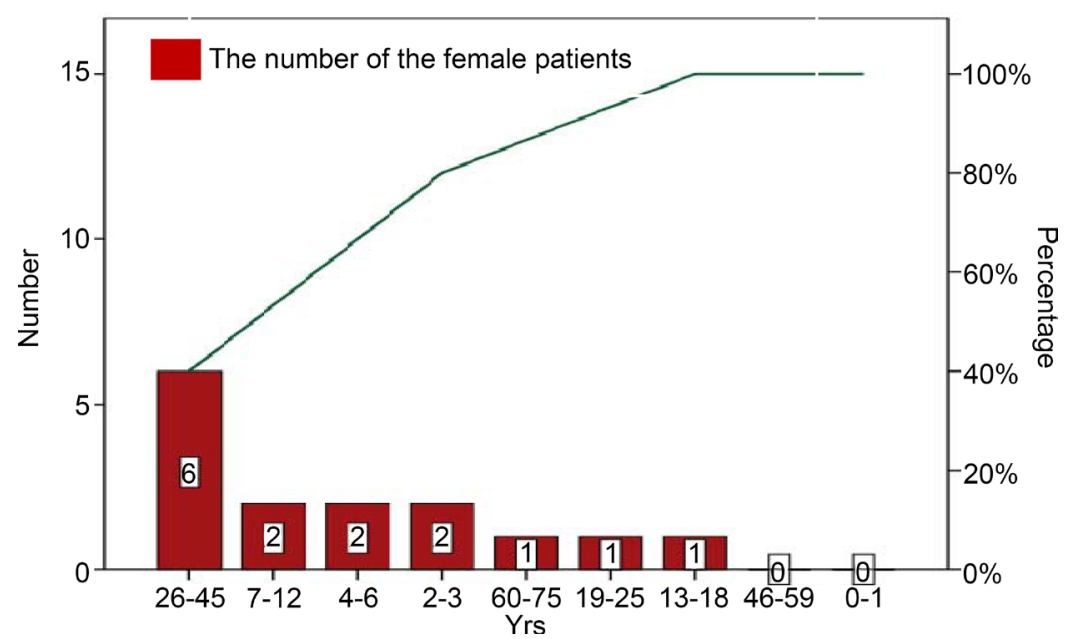

Figure 2. Pareto analysis summarizing the number of the female with hemophilia in different age intervals and Pareto analysis based on the cumulative percentages. 


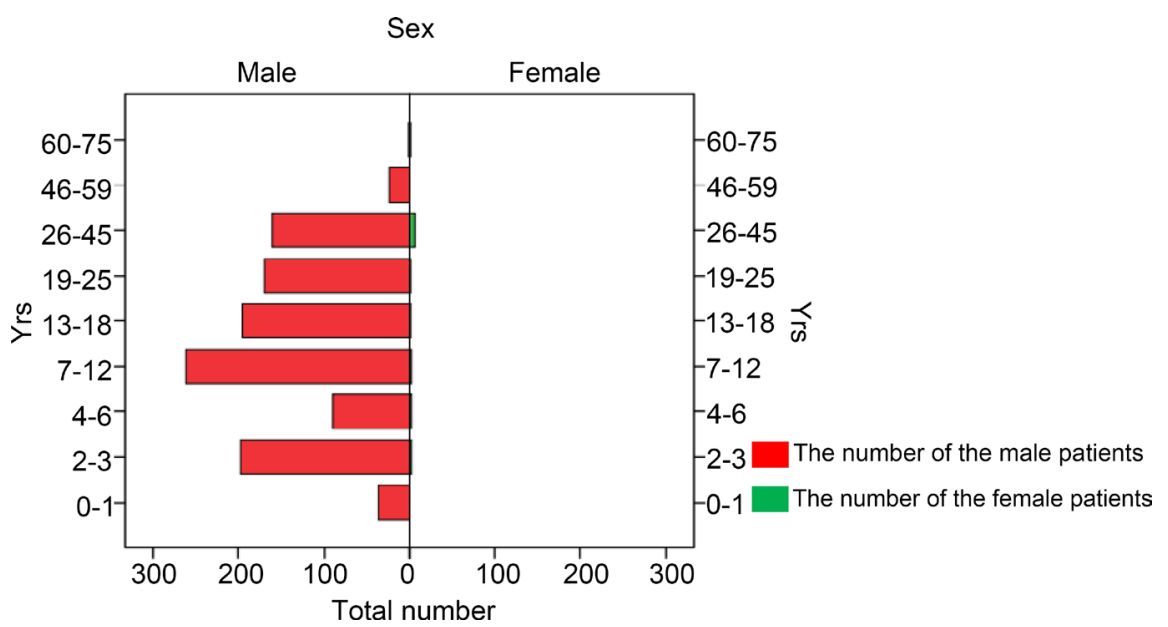

Figure 3. Population pyramid analyzes the number of patients in different age intervals.

of which disease pathogenesis is regular: if mother is a carrier, the probability of health or sick of her son will be respectively $50 \%$. So hemophilia affects boys and men primarily, women carry the gene and their sons develop it. The causative mechanism of Hemophilia-deficiency in Factor VIII or IX-was recognized in the 1950s. The differences between haemophilias A and B are pharmacokinetics of coagulation factors, frequency of occurrence (haemophilia A > haemophilia B), proportion of patients in each level of severity, mutations that cause the disorder (more point mutations in haemophilia $B$ than in haemophilia A), inhibitor development (more common in haemophilia A than in haemophilia B), risk of associated issues with inhibitor development (anaphylactoid reactions and nephrosis recorded in B and uncommon in A) [3].

Before modern substitution treatment was introduced at the end of the 1960s, hemophilia often resulted in severe disability at a young age and premature death [1] [2] [3]. However, in this study, there are some people with hemophilia in every age interval, such that there are 25 out of 1149 people aged over 45 years. The result at a societal level is that there are many more elderly people with hemophilia than in previous generations. It may be, life expectancy for people with hemophilia has improved and is now approaching that of the general population [9] [20] [21].

In order to facilitate and differentiate the comprehensive number of each age interval, we subdivide age intervals and find that the male with hemophilia are most around $7-12$ and $2-3$ years old, whereas the female with hemophilia are most around 26 - 45 years old. For male patients, most around $7-12$ and $2-3$ years old, coincide with the epidemiological characteristics of hemophilia [1] [2] [3] [4]. The reason for female patients, most around 26 - 45 years old may be that: on the one hand, women who carry one copy of the abnormal gene also can experience heavy bleeding symptoms and have mild hemophilia [6]. However, most of the women with a family history of hemophilia did not realize that they were at risk of bearing the gene [8]. On the other hand, most women have married at the age of 26 to 45 . They have formed their own family and had children. At this time, mild symptoms resulting from hemophilia can be more severe for 
women because of their associated effects on menstruation, pregnancy, childbirth [6] [10] [22] [23].

These data provide useful evidence on the trends in a measurable outcome of hemophilia. In recent years, though there is relatively small number of people with hemophilia, for meeting the challenge of the ageing hemophilia population, the management of hemophilia becomes more complex [9]. We will have come a long way to supply assistance treatment information for discovering new characteristic rules and seeking new treatment strategies [24] [25] [26]. One of the important challenging issues in the near future is registration available information for all affected individuals worldwide. Key elements of success include the enthusiasm and commitment of the Chinese professionals and patient leaders in their desire to advance hemophilia care and their commitment to work collaboratively in a coordinated manner.

\section{Conflict of Interest Statement}

None of the authors have any financial or other potential conflict of interest for this study.

\section{Acknowledgements}

This work is supported by the Central College Fund (PhD) (No. GK201504015).

\section{References}

[1] Ingram, G.I. (1976) The History of Haemophilia. Journal of Clinical Pathology, 29, 469-479. https://doi.org/10.1136/jcp.29.6.469

[2] Smit, C., Rosendaal, F.R., Varekamp, I., Bröcker-Vriends, A., et al. (1989) Physical Condition, Longevity, and Social Performance of Dutch Haemophiliacs. British $\mathrm{Me}$ dical Journal, 298, 235-238. https://doi.org/10.1136/bmj.298.6668.235

[3] Berntorp, E. and Shapiro, A.D. (2012) Modern Haemophilia Care. The Lancet, 379, 1447-1456. https://doi.org/10.1016/S0140-6736(11)61139-2

[4] Schramm, W. (2014) The History of Haemophilia-A Short Review. Thrombosis Research, 134, S4-S9. https://doi.org/10.1016/j.thromres.2013.10.020

[5] Mannucci, P.M. (2002) Hemophilia and Related Bleeding Disorders: A Story of Dismay and Success. In: American Society of Hematology Education Program, Hematology. American Society of Hematology. Education Program, The Society, Washington DC, 1-9.

[6] James, A.H. (2010) Women and Bleeding Disorders. Hemophilia, 16, 160-167. https://doi.org/10.1111/j.1365-2516.2010.02315.x

[7] Franchini, M. and Mannucci, P.M. (2012) Past, Present and Future of Hemophilia: A Narrative Review. Orphanet Journal of Rare Diseases, 7, 24.

https://doi.org/10.1186/1750-1172-7-24

[8] Rhynders, P.A., Sayers, C.A., Presley, R.J. and Thierry, J.M. (2014) Providing Young Women with Credible Health Information about Bleeding Disorders. American Journal of Preventive Medicine, 47, 674-680. https://doi.org/10.1016/j.amepre.2014.07.040

[9] Hermans, C., de Moerloose, P. and Dolan, G. (2014) Clinical Management of Older Persons with Haemophilia. Critical Reviews in Oncology/Hematology, 89, 197-206. https://doi.org/10.1016/j.critrevonc.2013.07.005 
[10] Myrin-Westesson, L., Baghaei, F. and Friberg, F. (2013) The Experience of Being a Female Carrier of Haemophilia and the Mother of a Haemophilic Child. Haemophilia, 19, 219-224. https://doi.org/10.1111/hae.12026

[11] Holstein, K., Eifrig, B. and Langer, F. (2014) Relationship between Haemophilia and Social Status. Thrombosis Research, 134, S53-S56. https://doi.org/10.1016/j.thromres.2013.10.012

[12] Dai, J., Lu, Y., Ding, Q., Wang, H., Xi, X. and Wang, X. (2012) The Status of Carrier and Prenatal Diagnosis of Haemophilia in China. Haemophilia, 18, 235-240. https://doi.org/10.1111/j.1365-2516.2011.02630.x

[13] Bastani, P., Pourmohamadi, K. and Karimi, M. (2012) Quality of Life in Hemophilia Complicated by Inhibitors. Iranian Red Crescent Medical Journal, 14, 250-251.

[14] Liu, Y. and Chen, L. (2011) Correlation between Quality of Life and Joint Health in Children with Haemophilia. Chinese Journal of Rehabilitation, 26, 112-114. (In Chinese)

[15] James, A.H., Ragni, M.V. and Picozzi, V.J. (2006) Bleeding Disorders in Premenopausal Women: (Another) Public Health Crisis for Hematology? ASH Education Book, 2006, 474-485. https://doi.org/10.1182/asheducation-2006.1.474

[16] Zhang, N., Peng, Y., Wu, R., et al. (2013) Value of International Prophylaxis Study Group (IPSG) Magnetic Resonance Imaging Scale System in the Evaluation of Hemophiliac Arthropathy Joint Changes in Children. Journal of Capital Medical University, 34, 342-347. (In Chinese)

[17] Lauritsen, J.M. and Bruus, M. (2003) EpiData (Version 3). A Comprehensive Tool for Validated Entry and Documentation of Data. The EpiData Association, Odense.

[18] Li, Z. and Luo, P. (2011) PASWSPSS Statistics Course in Chinese Version (Version 3). Publishing House of Electronics Industry, Beijing.

[19] Bolton-Maggs, P.H. and Pasi, K.J. (2003) Hemophilias A and B. The Lancet, 361, 1801-1809. https://doi.org/10.1016/S0140-6736(03)13405-8

[20] Darby, S.C., Kan, S.W., Spooner, R.J., Giangrande, P.L., et al. (2007) Mortality Rates, Life Expectancy, and Causes of Death in People with Hemophilia A or B in the United Kingdom Who Were Not Infected with HIV. Blood, 110, 815-825. https://doi.org/10.1182/blood-2006-10-050435

[21] Zimmermann, R., Staritz, P. and Huth-Kühne, A. (2014) Challenges in Treating Elderly Patients with Haemophilia A Focus on Cardiology. Thrombosis Research, 134, S48-S52. https://doi.org/10.1016/j.thromres.2013.10.023

[22] James, A.H. (2005) More Than Menorrhagia: A Review of the Obstetric and Gynaecological Manifestations of Bleeding Disorders. Haemophilia, 11, 295-307. https://doi.org/10.1111/j.1365-2516.2005.01108.x

[23] Byams, V.R. (2007) Women with Bleeding Disorders. Journal of Women's Health, 16, 1249-1251. https://doi.org/10.1089/jwh.2007.CDC11

[24] Sylvia, R., Werner, S., Thomas, S., Florian, W., et al. (2009) Austrian Hemophilia Registry: Design, Development and Set of Variables. The Middle European Journal of Medicine, 121, 196-201.

[25] Murray, C.J.L., Ortblad, K.F., Guinovart, C., Lim, S.S., et al. (2014) Global, Regional, and National Incidence and Mortality for HIV, Tuberculosis, and Malaria during 1990-2013: A Systematic Analysis for the Global Burden of Disease Study 2013. The Lancet, 384, 1005-1070. https://doi.org/10.1016/S0140-6736(14)60844-8

[26] Uguen, D., Lönngren, T., Le Cam, Y., Garner, S., et al. (2014) Accelerating Development, Registration and Access to Medicines for Rare Diseases in the European Union through Adaptive Approaches: Features and Perspectives. Orphanet Journal of Rare Diseases, 9, 20. https://doi.org/10.1186/1750-1172-9-20 
Submit or recommend next manuscript to SCIRP and we will provide best service for you:

Accepting pre-submission inquiries through Email, Facebook, LinkedIn, Twitter, etc. A wide selection of journals (inclusive of 9 subjects, more than 200 journals)

Providing 24-hour high-quality service

User-friendly online submission system

Fair and swift peer-review system

Efficient typesetting and proofreading procedure

Display of the result of downloads and visits, as well as the number of cited articles Maximum dissemination of your research work

Submit your manuscript at: http://papersubmission.scirp.org/

Or contact health@scirp.org 